\section{Rays of hope for rare ovarian cancers}

A great fallacy of statistical method applied to clinical medicine is the assumption that one equals one. For example, the death of an 80 year old from ovarian cancer is sad-but not comparable to the loss of an 18 year old just flowering into full womanhood from what, for certification purposes, is the same disease. Avoidance of the former death would serve only to delay a few months or years the old lady's ultimate entry in the Registrar General's records, possibly transferring it to a coding less likely to be associated with a miserable demise. On the other hand, it would be a triumph if the death of the 18 year old, with its impact on the lives of family and friends, could be averted.

Ovarian cancers may be divided into two categories approximating to these age extremes. Most develop from the surface epithelium and occur in relatively senior women; a few arise from germinal epithelium and affect young women. Any progress in preventing deaths in this group would not be evident in the total mortality statistics; even if it were, the mere numbers would not disclose the true value of preventing these deaths.

The extensive classification of ovarian tumours proposed by the World Health Organisation has the daunting impact of a metropolitan telephone directory. At one time its use seemed rather an academic exercise of relevance only to pathologists devoting their lives to the subject-but this is no longer true. If each type of rare germ cell tumour is studied and managed individually, greatly improved results may be obtained. A recent report suggests that pessimistic attitudes about malignant teratomas and advanced dysgerminomas should be revised. ${ }^{1}$ Thirteen of 18 patients (mean age 19.3 years) with metastatic malignant (immature) teratomas who received combination chemotherapy were in complete clinical and biochemical remission after a mean of 27.5 months off treatment. Three patients with advanced dysgerminomas were also in complete remission five, 14, and 33 months after stopping chemotherapy. Most metastatic germ cell tumours now seem curable provided that effective treatment is begun early. Eleven teratomas produced $\alpha$-fetoprotein or human chorionic gonadotrophin and six produced both. The one producing no marker proved fatal, as did three producing both, but high concentrations from the outset had indicated a poor prognosis. Pulsed chemotherapy was continued until complete clinical and biochemical remission had been maintained for 12 weeks. The initial pulses consisted of vincristine, methotrexate with folinic acid rescue, bleomycin, and cisplatin followed by VP 16-213 (etoposide), actinomycin $\mathrm{D}$, and cyclophosphamide. A third regimen was dropped after evidence of resistance appeared. Cisplatin was omitted from the first regimen after achieving remission. All the patients with postpubertal teratomas were menstruating normally, so that presumably their fertility was reasonably good.

Endodermal sinus tumours produce $\alpha$-fetoprotein and carry a high mortality. With combination chemotherapy and monitoring of $\alpha$-fetoprotein after unilateral salpingooophorectomy successful remission has been achieved ${ }^{2}$ and followed by pregnancy. ${ }^{3}{ }^{4}$ Wiltshaw et al have recently reported complete remission with conservation of the uterus and one ovary in seven of eight cases. ${ }^{5}$

These cases emphasise that cure is not the only consideration with germ cell malignancy in girls. Dysgerminoma is the most common tumour and is very radiosensitive. Aggressive treatment can cure almost all stage I cases, but loss of ability to bear children may be an unnecessarily high price. Sixty seven of 72 patients with stage Ia pure dysgerminomas treated $\varrho$ by unilateral salpingo-oophorectomy alone were alive and free from disease at five years. ${ }^{6}$ When the tumour was of mixed type the five year survival was only $25 \%$, which emphasises the importance of looking at "pure" tumour types. Thee conservative policy relies on the efficacy of radiation for dealing with recurrence. Chemotherapy has rarely been used with:localised dysgerminomas because of the excellent results with radiotherapy; but if used judiciously it may achieve the sameo end with preservation of fertility.

Weinblatt and Ortega ${ }^{7}$ have reported successes and advocate $\frac{\overline{\bar{\omega}}}{\bar{\sigma}}$ giving chemotherapy initially for extensive dysgerminoma in̊ childhood in the hope that if the tumour responds surgery mays be unnecessary or can be less radical. De Palo et al, reviewing $\overrightarrow{0}$ 56 pure dysgerminomas, describe four patients treated by conservative surgery and chemotherapy with survival at $60, \vec{\omega}$ 61,77 , and 89 months. $^{8}$

The most extensive staging procedures are necessary in these cases as is the opinion of an expert pathologist on theo precise nature of the tumour. Then the aim is to achieve the maximum chance of cure with the minimum risk of sterilisation, giving any chemotherapy with optimal efficiency. Opinion $s_{\infty}^{\infty}$ vary on the referral of patients with cancer to specialist regional centres. Undoubtedly, however, young women withe germ cell tumours should be dealt with where special skil $\mathrm{N}$ exists, as are patients with trophoblastic neoplasia. There is a striking similarity between the advances made with chemotherapy in these cancers in young women and those achieved earlier with trophoblastic malignancy.

When chemotherapy achieves a cure with preservation ofe potential fertility, the likely outcome in terms of childbearingo is obviously of great importance. Barber ${ }^{9}$ concluded that though further studies are needed, the evidence justifies optimism. Though conception rates may be reduced, there is no evidence of any substantial increase in pregnancy wastage or fetal abnormality.

There are also opportunities for prophylaxis. Germ celB tumours are common in intersexual girls, particularly those with dysgenetic gonads and an XY cell line-the frequency may. be as high as $25-50 \% .{ }^{10}$ Usually the tumour is a gonadoblastoma sometimes combined with dysgerminoma. Excision of functionless gonadal streaks is well worth while. Some intersexuals without XY cells develop germ cell tumours unpredictably; as our knowledge of the influence of the $\mathrm{H}-\mathrm{YO}_{3}$ antigen improves we may be able to give a better guide to their risk of cancer.

This whole story represents a triumph for painstaking application of the classic clinicopathological approach, highlo specific diagnosis and precise staging paving the way for effectively monitored treatment. The prospects are that furthe progress against ovarian cancer will continue to come from $w$ skilled marksmen sniping away at the small print section ok the classification. Success with a juvenile counts as a bull's eye with a bonus for preserving fertility; an octogenarian rates only as an outer.

Professor of Obstetrics and Gynaecology,

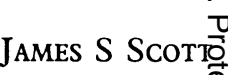
University of Leeds,

Leeds LS2 9NG

1 Newlands ES, Begent RHJ, Rustin GJS, Bagshawe KD. Potential for cure in metastatic ovarian teratomas and dysgerminomas. $\mathrm{Br} \mathcal{F}$ Obstef Gynaecol 1982;89:555-60.

2 Gallion H, van Nagell JR Jr, Powell DF, Donaldson ES, Hanson Mō̄ Therapy of endodermal sinus tumor of the ovary. Am $\mathcal{F}$ Obstet Gyneco $1979 ; 135: 447-51$ 
${ }^{3}$ Forney JP. Pregnancy following removal and chemotherapy of ovarian endodermal sinus tumor. Obstet Gynecol 1978;52:360-2.

4 Duncan ID, Young JL. Endodermal sinus tumour of the ovary: serum alpha-fetoprotein levels before and after treatment and during pregnancy. Br F Obstet Gynaecol 1980;87:535-8.

5 Wiltshaw E, Stuart-Harris R, Barker GH, Gowing NFC, Raju S. Chemotherapy of endodermal sinus tumour (yolk sac tumour) of the ovary: preliminary communication. Fournal of the Royal Society of Medicine $1982 ; 75: 888-92$.

${ }^{6}$ Gordon A, Lipton D, Woodruff JD. Dysgerminoma: a review of 158 cases from the Emil Novak Ovarian Tumor Registry. Obstet Gynecol $1981 ; 58: 497-504$.

${ }^{7}$ Weinblatt ME, Ortega JA. Treatment of children with dysgerminoma of the ovary. Cancer $1982 ; 49: 2608-11$.

${ }^{8}$ De Palo G, Pilotti S, Kenda R, et al. Natural history of dysgerminoma. Am $\mathcal{f}$ Obstet Gynecol 1982;143:799-807.

${ }^{9}$ Barber HRK. The effect of cancer and its therapy upon fertility. Int $\mathcal{F}$ Fertil $1981 ; 26: 250-9$.

${ }^{10}$ Scott JS. Intersex and sex chromosome abnormalities. In: Macdonald RR, ed. Scientific basis of obstetrics and gynaecology. Edinburgh: Churchill Livingstone, 1978:301-44.

\section{Stars and stripes-for ever?}

Each year the Fournal of the American Medical Association devotes an issue to medical education. Last December the 82nd annual report described what is now happening and what hopes there are for the future in this great American arena. The best general reading is in the section on future directions, where the comforting self assurance of good American prose clothes many right sentiments. The report speaks strongly, for example, of the danger that increasingly specialised training, even at undergraduate level, will leave too little room for the arts, the humanities, and the generality of medical practice: "If it is accepted that medicine concerns people and that knowledge of human behaviour is enhanced by an understanding of literature, art, history and philosophy" then medical schools should be selecting and planning accordingly.

How familiar the exhortations are: on the fallibility of examinations, the need to develop and assess qualities other than factual recall, the importance of social awareness and medical practice outside the hospital, the need to define the true purpose of the undergraduate course-not as a complete training but as a foundation-and the neglected art and practice of evaluation, of both students and teachers. Have they made any progress in the United States? Have we, since our own General Medical Council quoted T S Eliot to us: "Where is the wisdom we have lost in knowledge? Where is the knowledge we have lost in information?" On both sides of the Atlantic there are ways of looking at what medical schools are doing, and there are teeth that can be bared if need be; but it would have been interesting to hear more about how the desired changes are to be achieved, or even about what exciting developments are in progress.

Medical education sometimes seems to be pervaded by the spirit of the stick and the carrot. Continuing education in the United States exemplifies confusion about how to achieve the desired end-by awarding good conduct stars through schemes such as the physicians' recognition award, or by threatening various stripes for default. The $\mathfrak{f} A M A$ report on continuing education has an enthusiastic account of what technology can do for informatics and, for the rest, a good many dull facts and sterile definitions. Two statements tell most of the story: "It has been difficult to document a positive correlation between a physician's participation in continuing medical education and improved patient care" and, "It is clearly evident that the trend towards mandatory continuing medical education has come to a halt."

The bland conclusion that "Continuing medical education in its various modes is a prerequisite for the competent practice of medicine" is a fair declaration of faith. What remains is not so much to prove it as to make it true, and if there are not more stimulating activities in this direction than are dreamt of in this report's philosophy, then there is something to be learnt from general practice in the United Kingdom. The key is the relation of continuing education to standards of practice-the integration of learning, and teaching with audit, so that continuing education becomes the means and the measure of improvement in the quality of medical care.

The report includes many facts about undergraduate medical schools in the United States and their finances. Overall there are two applicants for every available place, with women constituting $30 \%$ of students admitted and $25 \%$ of those currently qualifying. The drop out rate during the medical school course is only about $2 \%$. The output of medical graduates increased by $54 \%$ in the 10 years up to 1982 , but this rate of growth has now declined to about a third of that between 1972 and 1977. About $95 \%$ of United States medical school graduates take up first year residencies-almost 16000 doctors a year. This number of first year residents is augmented by just under 5000 foreign medical graduates and a substantial number of United States citizens who are graduates of foreign medical schools.

There is little evidence of manpower planning at the postgraduate stage or of successful efforts to relate the numbers of training opportunities to the needs of the community. The generally passive approach is reflected in the comment, "The choice of location and the choice of specialty will undoubtedly be limited for many persons," and by the relative numbers of residency positions available-well over 9000 in surgery and urology, compared with under 2000 in anaesthesiology. Residency training in emergency medicine is singled out as a new specialty, with programmes first accredited in 1982.

The general picture this report presents is one of activity and awareness of problems that remain. It is always difficult to write specifically about medical education while acknowledging its interrelation with service and manpower. The report describes, for instance, current policies and attitudes on acceptance into postgraduate training programmes for graduates from foreign medical schools and United States citizens who have graduated elsewhere, but it makes no comment on the extent to which these doctors become absorbed into the practising profession and what views there are about this. The complex relations between the various bodies concerned with the control of medical education, particularly at the postgraduate stage, are well described. The importance of the autonomy of the specialty boards is rightly emphasised, and the comment that "any attempt to politicise the boards should be resisted vigorously" is well made.

There are many other chords of sympathy between the American way of thinking and our own. It is a question of how to reconcile the separateness and independence of individual specialties, the maintenance of proper educational standards, and the right of the profession to self determination and self control with the need for a system which can meet the requirements of the community. $\mathcal{F} A M A$ pleads for a single organisation-the American Medical Association Council of Medical Education-to take the initiative in identifying and addressing the major issues in medical education. Identifying and addressing issues is not, however, the same as solving problems, because the problems of medical education interlock with those 